\title{
Controle da ferrugem da folha do trigo (Puccinia triticina) em diferentes momentos de aplicação de fungicida
}

\section{Control of wheat leaf rust (Puccinia triticina) at different timings of fungicide application}

\author{
Gustavo Migliorini de Oliveira1*, Diego Dionizio Pereira', Lenio Cesar Moraes de Camargo', \\ Marcelo Gonçalves Balan², Marcelo Giovanetti Canteri ${ }^{1}$, Seiji Igarashi ${ }^{1}$, Otavio Jorge Grigoli Abi Saab ${ }^{1}$
}

RESUMO: A aplicação de fungicidas tem importante papel na cultura do trigo e sua eficácia está atrelada principalmente ao momento biológico para o controle. O objetivo deste trabalho foi estudar a influência do momento de aplicação de fungicida nos danos decorrentes da ferrugem da folha do trigo (P. triticina). Um coletor de esporos Siga foi instalado na área experimental a fim de auxiliar na previsão da ocorrência da ferrugem antes da manifestação dos sintomas. O cultivar utilizado foi o CD 104 susceptível à ferrugem - e as aplicaçôes foram realizadas aos 7 , 14 e 21 dias após a manifestação dos primeiros sintomas de ferrugem nas plantas. Avaliaram-se neste experimento a área abaixo da curva de progresso da doença, obtida pela sua severidade, e os índices de produtividade ( $\mathrm{kg} / \mathrm{ha}$ ) e peso hectolitro $(\mathrm{g})$ da cultura. O coletor Siga foi capaz de detectar esporos de ferrugem antes da manifestação sintomática da doença, auxiliando na sua identificação no campo nos primeiros sintomas. $\mathrm{O}$ atraso nas aplicaçóes de fungicida aumentou os níveis de severidade, reduzindo significativamente o nível de controle e ocasionando danos consideráveis à produtividade da cultura. Verificaram-se perdas de produtividade na ordem de $80 \mathrm{~kg}$ por dia de atraso na aplicação.

PALAVRAS-CHAVE: controle químico; momento biológico de controle; coletor de esporos.

\begin{abstract}
The fungicide application is important to the wheat field and its efficacy is related mainly to the biologic timing for the control. The aim of this paper was to study the influence of timing of fungicide application in the damage caused by leaf rust of wheat ( $P$. triticina). A spore trap Siga was installed in the experimental area to assist the prediction of leaf rust before the first symptom. The cultivar used was CD 104 - susceptible to the rust - and the applications were made at 7,14 and 21 days after the first symptoms of the leaf rust on the plants. It was evaluated in this experiment the area under the disease progress curve, obtained by the disease severity, and the yield ( $\mathrm{kg} / \mathrm{ha}$ ) and hectolitre weight (g) indexes of the field. The trap Siga was able to detect spores of leaf rust before the disease symptoms, supporting its identification in the field in the first symptoms. The delay of the fungicide application increased the level of disease severity, reducing significantly the control level and causing considerable damage to the crop yield. It was verified yield losses approximately of $80 \mathrm{~kg}$ per day of delay of the application.
\end{abstract}

KEYWORDS: chemical control; timing of fungicide application; spore trap. 


\section{INTRODUÇÃO}

A ferrugem da folha do trigo, ocasionada pelo fungo Puccinia triticina Eriks, caracterizado como parasita obrigatório, é uma das principais doenças da cultura. Ela é observada, não necessariamente de forma epidêmica, em praticamente todos os anos de cultivo entre os cultivares susceptíveis. O controle químico, por sua vez, é o principal método de controle, sendo a aplicação de fungicidas uma constante na cultura do trigo, com efetividade de controle (Debona et al., 2009; Kunnem Junior et al., 2009; Godoy et al., 2000; Picinini; Fernandes, 2001).

O principal fator inerente à eficácia da aplicação de fungicida contra a ferrugem da folha está ligado ao momento biológico de controle. Todavia, sáo frequentes aplicaçôes calendarizadas, ou seja, determinadas principalmente por um respectivo estádio fenológico da cultura. A aplicação baseada neste método não é totalmente eficaz e/ou recomendável no âmbito epidemiológico, pois não considera a presença da doença, podendo resultar em aplicaçóes desnecessárias, aumentando o impacto ambiental. Além deste aspecto, tais aplicaçóes podem apresentar baixo nível de controle, uma vez que o fungicida é metabolizado pelas plantas ao longo do tempo, podendo apresentar efeito fungistático diminuto quando há uma eventual infecção do patógeno.

Neste sentido, vêm sendo desenvolvidos os chamados modelos preditivos ou sistemas de aviso, que consideram parâmetros meteorológicos, do hospedeiro e/ou do patógeno, tendo como prerrogativa prever períodos em que haja condiçôes favoráveis para o desenvolvimento de determinada doença tanto em nível local quanto regional (YANG, 2006).

Para a cultura do trigo, são encontrados na literatura alguns sistemas de previsáo (Cardoso, 2006; Shah; Bergostrom, 2002). Existe ainda um sistema desenvolvido a partir de um coletor de esporos denominado SIGA (GARDIANO et al., 2010; IgARASHI $e t$ al., 2008), que tem o intuito de detectar a presença de esporos de organismos fitopatogênicos no ar e associar a dados meteorológicos e de previsão de tempo a fim de estimar a possibilidade de infecção de doenças.

Os sistemas de previsão auxiliam na identificação inicial da doença na cultura, no planejamento e tomada de decisão da aplicação de fungicidas no campo, na reduçáo de eventuais contaminaçóes ambientais e outras consequências indesejáveis decorrentes de aplicaçóes de fungicida desnecessárias, na reduçấo das chances de desenvolvimento de resistência da ferrugem a fungicidas - aplicaçôes preventivas com menor pressão de inóculo (Guini; Kimati, 2002) e, sobretudo, no aumento da eficiência de controle e reduçáo dos danos causados pela ferrugem da folha na cultura do trigo (CooK et al., 1999).

Baseado nestas premissas, o objetivo deste trabalho foi estudar o efeito de diferentes momentos de aplicação de fungicida nas perdas decorrentes da ferrugem da folha do trigo, com o auxílio do coletor de esporos SIGA.

\section{MATERIAL E MÉTODOS}

O trabalho foi desenvolvido na fazenda escola da Universidade

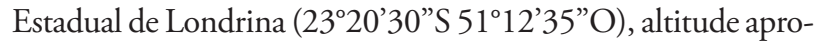
ximada de $560 \mathrm{~m}$, na safra agrícola de 2010. De acordo com a classificação climática de Köppen, o clima da região é do tipo $\mathrm{Cfa}$ (verão quente e chuvoso, com precipitação pluviométrica média anual de $1.600 \mathrm{~mm}$ ), sendo o solo da regiáo classificado como latossolo vermelho eutroférrico (EMBRAPA, 1999).

Utilizou-se o cultivar CD 104, ciclo médio ( -120 dias), caracterizado como moderadamente susceptível às principais doenças da cultura do trigo: Puccinia triticina, Blumeria graminis, Phaeosphaeria nodorum, Cochliobolus sativus, Pyrenophora tritici-repentis, Magnaporthe grisea e Giberella zeae. O cultivar foi semeado em 23 de abril de 2010, tendo $250 \mathrm{~kg} / \mathrm{ha}$ da fórmula 4-14-8 (N-P-K) como adubação no momento da semeadura.

O coletor de esporos SIGA, associado aos dados meteorológicos e de previsão de tempo (Gardiano et al., 2010; IgARASHi et al., 2008), foi utilizado como método de monitoramento das doenças do trigo antes da manifestaçáo dos sintomas, auxiliando na correta identificaçáo da doença antecipadamente. O coletor apresentava-se a $50 \mathrm{~cm}$ da copa do trigo, sendo sua altura variável com o crescimento da cultura. Neste coletor, foram fixadas lâminas de microscopia óptica com fita adesiva transparente de face dupla para aderência dos esporos presentes no ar. As lâminas foram trocadas em um intervalo de três dias. A identificação dos patógenos se deu por meio da observação dos esporos em microscópio óptico.

O delineamento experimental foi em blocos casualizados com quatro repetiçôes, referente a diferentes momentos biológicos de controle da ferrugem da folha do trigo, sendo que cada parcela apresentava área de $32 \mathrm{~m}^{2}(4 \times 8 \mathrm{~m})$. Os tratamentos constituíram-se de três momentos de aplicaçáo de fungicida. $\mathrm{O}$ primeiro iniciou a partir do diagnóstico dos sintomas na cultura e os demais, posteriormente, em intervalos de sete dias. Também havia a testemunha sem controle.

Utilizou-se a dose comercial de 0,5 L.ha ${ }^{-1}$ do fungicida epoxiconazol + piraclostrobina $+0,5 \%$ v.v de óleo mineral. A aplicação foi realizada por meio de um pulverizador costal pressurizado via $\mathrm{CO}_{2}$, acoplado com a ponta de pulverizaçáo XR 110-02 — jato plano simples - na pressão de trabalho de $413 \mathrm{kPa}$, gerando, consequentemente, taxa de aplicação de $250 \mathrm{~kg} / \mathrm{ha}$ com gotas classificadas como finas, segundo o fabricante. Considerou-se um intervalo aproximado de 20 dias para as reaplicaçóes do fungicida em cada respectivo tratamento, sendo estas realizadas até a maturaçáo fisiológica das plantas, totalizando três aplicaçôes em cada tratamento.

No momento da aplicaçáo do primeiro tratamento, a cultura apresentava-se no estádio de elongaçáo do colmo, com $25 \%$ de incidência de ferrugem entre as plantas de trigo como um todo. As datas, bem como as condições meteorológicas relativas ao momento de cada aplicaçấo, estáo descritas na Tabela 1. 
Avaliaçóes de severidade da doença foram realizadas periodicamente a cada sete dias com o auxílio de escala diagramática para a doença (BRunetTa et al., 1997). A partir destas, construíram-se curvas de progresso da doença e calculou-se a área abaixo da curva de progresso da doença (AACPD). A estimativa da produtividade e o peso hectolitro, padronizados em $13 \%$ de umidade, foram obtidos a partir da colheita manual de $3 \mathrm{~m}^{2}$ da cultura — área central da parcela. Análises de variância seguidas do teste Tukey em 5\% de probabilidade foram efetuados para a determinação dos efeitos de cada tratamento nas variáveis analisadas.

\section{RESULTADOS E DISCUSSÃO}

Todas as aplicaçóes de fungicida foram efetuadas no período da manhá, quando a temperatura, a umidade relativa do ar e velocidade do vento $(<4 \mathrm{~km} / \mathrm{h})$ se encontravam adequadas para tanto (RAmos; PIo, 2008). As datas e condições de temperatura e umidade relativa do ar de cada aplicação podem ser verificadas na Tabela 1 .

$\mathrm{O}$ coletor de esporos Siga mostrou-se eficaz quanto à identificação esporos de doenças de trigo antes da manifestação dos sintomas na cultura. Os primeiros esporos da ferrugem da folha do trigo ( $P$. triticina) foram detectados inicialmente em 2 de junho, enquanto a manifestação sintomática sobre as plantas foi observada somente 7 dias depois. Identificou-se ainda, por meio do coletor de esporos, a presença de propágulos de $P$. tritici-repentis e $C$. sativus, porém, no final do desenvolvimento da cultura, o que pouco influenciou nos danos. Na Figura 1 são demonstradas as datas do surgimento dos primeiros esporos e sintomas da ferrugem da folha e a mancha amarela do trigo, bem como as condiçóes meteorológicas ocorridas.

Os sistemas de previsão de doenças têm como prerrogativa fundamental identificar a possibilidade de ocorrência de uma determinada doença ou até mesmo sua epidemia antes de sua real infecção no campo. Neste sentido, podem determinar se ela ocorrerá ou não, além de auxiliar na identificação antecipada no campo e no seu monitoramento após o seu estabelecimento na cultura. Isto possibilita o planejamento do agricultor com relação a uma eventual aplicação de fungicida. Na iminência de risco de dano econômico, os sistemas de previsão podem promover controle mais eficiente ou até mesmo propiciar a economia de aplicaçóes em relação aos sistemas de aplicação calendarizada, resultando em menor impacto ambiental (Del Ponte et al., 2004).

Em relação aos resultados da AACPD para a ferrugem, a análise estatística demonstrou que o atraso na aplicação de fungicida propiciou aumento no nível de severidade da doença (Tabela 2), reduzindo, por conseguinte, o nível de controle.

A partir da Figura 2, nota-se que o nível de severidade da doença começa a se diferenciar de forma evidente entre os tratamentos a partir do dia 24 de junho -15 dias após a manifestação dos primeiros sintomas da doença no campo - , apesar do baixo índice de precipitação pluviométrica neste período (Fig. 1). O desenvolvimento da doença em condiçóes de baixa precipitação pluviométrica pode ser

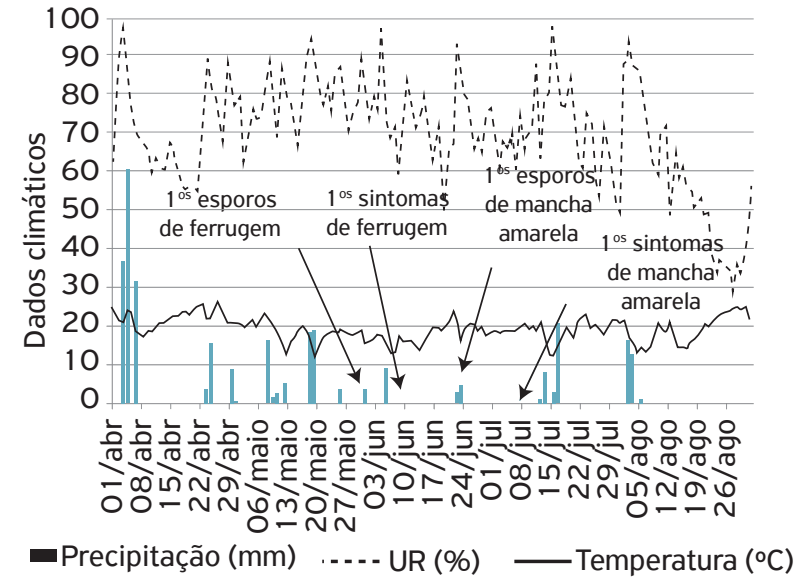

UR: Umidade relativa do ar.

Fonte: Instituto Agronômico do Paraná - IAPAR.

Figura 1. Dados diários de precipitação pluviométrica $(\mathrm{mm})$ e temperatura $\left({ }^{\circ} \mathrm{C}\right)$ relacionados à detecção dos primeiros esporos e sintomas da ferrugem da folha e mancha amarela do trigo, em Londrina (PR), na safra agrícola 2010.

Tabela 1. Datas e condições meteorológicas observadas durante as aplicações de fungicida para os três diferentes momentos de aplicação estudados para o controle da ferrugem da folha do trigo em Londrina, 2010.

\begin{tabular}{|c|c|c|c|c|c|c|c|c|c|}
\hline \multirow{2}{*}{$\begin{array}{l}\text { Aplicação de } \\
\text { fungicida (DAS) }\end{array}$} & \multicolumn{3}{|c|}{$1^{\circ}$ aplicação } & \multicolumn{3}{|c|}{$2^{\circ}$ aplicação } & \multicolumn{3}{|c|}{$3^{\circ}$ aplicação } \\
\hline & Data & $\begin{array}{c}\text { Temperatura } \\
\left({ }^{\circ} \mathrm{C}\right)\end{array}$ & UR (\%) & Data & $\begin{array}{c}\text { Temperatura } \\
\left({ }^{\circ} \mathrm{C}\right)\end{array}$ & UR (\%) & Data & $\begin{array}{c}\text { Temperatura } \\
\left({ }^{\circ} \mathrm{C}\right)\end{array}$ & UR (\%) \\
\hline 0 & 09/jun & 25,2 & 75 & 29/jun & 26,1 & 68 & 19/jul & 24,8 & 71 \\
\hline 7 & $16 /$ jun & 23,7 & 79 & 05/jul & 27,5 & 67 & 26/jul & 25,7 & 75 \\
\hline 14 & 23/jun & 25,1 & 71 & 12/jul & 22,9 & 70 & 01/ago & 28,6 & 68 \\
\hline
\end{tabular}

DAS: dias após a manifestação dos primeiros sintomas; UR: Umidade relativa do ar. 
Tabela 2. Área abaixo da curva de progresso de doença e porcentagem de controle em relação à testemunha sem controle, em função de diferentes momentos de aplicação de fungicida para o controle da ferrugem da folha do trigo, em Londrina (PR), 2010.

\begin{tabular}{lcc} 
Aplicação de fungicida (DAS) & AACPD & Controle (\%) \\
\hline 0 & $271,1 \mathrm{~d}$ & 86,6 \\
\hline 7 & $704,9 \mathrm{c}$ & 65,3 \\
\hline 14 & $1.414,8 \mathrm{~b}$ & 30,3 \\
\hline Testemunha sem controle & $2.031,5 \mathrm{a}$ & - \\
\hline CV (\%) & 10,99 & \\
\hline
\end{tabular}

DAS: dias após os primeiros sintomas; AACPD: área abaixo da curva de progresso de doença; CV: coeficiente variável.

Médias seguidas de mesma letra não diferem entre si pelo teste Tukey a 5\% de probabilidade.

decorrente do molhamento foliar oriundo principalmente do orvalho e gutação, características peculiares da estação do ano e da cultura do trigo, respectivamente.

A diferenciação substancial do percentual de severidade da ferrugem da folha entre os tratamentos aconteceu em torno de 15 dias após a aplicaçáo de fungicida no tratamento mais preventivo (0 dias após os sintomas - DAS). Possivelmente havia novas infecçốes incubadas sem manifestação de sintomas até então, iniciando-se a partir desta data um padrão agregado das lesôes devido às autoinfecções (PIres et al., 2009). Este fato é presumido, pois os fungicidas sistêmicos influenciam tanto na proteçáo do tecido vegetal a novas infecçôes quanto também na redução da produção de esporos em pústulas já instaladas nas plantas (BucK et al., 2011). Este fato demonstra a necessidade da detecção antecipada da doença, uma vez que o controle ineficiente, no caso de uma aplicação tardia, somente poderá ser observado posteriormente.

No tocante aos níveis de danos proporcionados pela doença, verificados pelos índices de produtividade, nota-se que o atraso no início das aplicaçóes de fungicidas gerou reduçôes significativas de produtividade. Em contrapartida, não foram observadas diferenças significativas entre os momentos de aplicação para a variável peso de mil sementes (Tabela 3).

Aplicaçôes efetuadas ao 0 e 7 DAS proporcionaram os maiores níveis de produtividade. Este fato demonstra que a detecção inicial da doença e o seu respectivo controle por meio da aplicação de fungicida são fatores de indubitável importância para a redução das perdas. Neste sentido, a utilização de métodos preditivos, como é o caso do coletor de esporos, torna-se necessária. A aplicação atrasada em 14 dias gerou estatisticamente a mesma produtividade do que a testemunha sem controle, o que denota que a aplicação de fungicida neste momento não apresentou eficácia, apesar de resultar em menor desenvolvimento epidêmico da ferrugem em relação à testemunha sem controle, verificada pela área baixa da curva de progresso da doença.

Boller et al. (2008) afirmaram que, uma vez iniciado o desenvolvimento epidêmico da ferrugem da folha, atrasos no momento da aplicação resultam em dificuldades maiores para o seu controle. Estes autores encontraram reduçôes nos

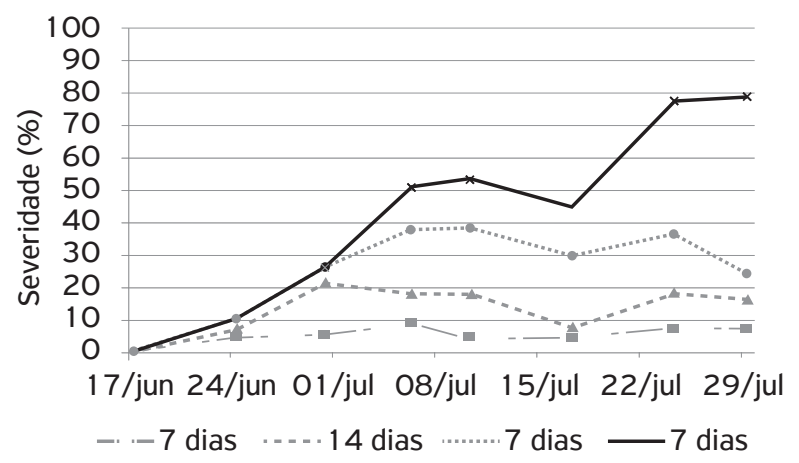

Figura 2. Curvas de progresso da doença observadas para diferentes momentos de aplicação de fungicida para o controle da ferrugem da folha, em Londrina (PR), 2010.

índices de produtividade quando da aplicação de fungicida com $10 \%$ de severidade em relação a $1 \%$, mesmo utilizando o dobro da dose ou intervalos menores entre as reaplicaçóes.

Trabalhos sobre o controle químico da ferrugem da folha do trigo são encontrados na literatura e apresentam, de maneira geral, grande eficiência de controle proporcionada pelos fungicidas dos grupos dos triazóis e estrobilurinas, tanto na forma isolada quanto em mistura (Debona et al., 2009; Kunnem Junior et al., 2009; Godoy et al., 2000; Picinini; Fernandes, 2001). Tal fato dá a conotação, assim como mencionado por Сook et al. (1999), de que o momento de aplicação de fungicidas é um dos principais fatores do sucesso do controle químico deste patossistema.

Arduim (2009), estudando a sensibilidade de fungicidas (in vitro e in vivo), encontrou diferenças entre os do grupo dos triazóis (inibidores da síntese de esteróis) para algumas raças de $P$. triticina, já para o grupo das estrobilurinas (inibidores da respiração mitocondrial) não foi verificada reduçâo na sensibilidade. Porém, sabe-se que vários outros patógenos (Blumeria graminisi, Mycosphaerella fijiensis, Venturia inaequalis e Plasmopara viticola) podem apresentar resistência às estrobilurinas, conforme verificado por Grasso et al. (2006).

Portanto, tais fatos, investigados por ARDuim (2009) e Grasso et al. (2006), demonstram a importância da necessidade 
Tabela 3. Produtividade e diferença de produtividade em relação à testemunha sem controle e peso hectolitro, em função de diferentes momentos de aplicação de fungicida para o controle da ferrugem da folha do trigo em Londrina (PR), 2010.

\begin{tabular}{lccc} 
Aplicação de fungicida (DAS) & Produtividade $(\mathrm{kg} / \mathrm{ha})$ & Diferença de produtividade (kg/ha) & Peso hectolitro (g) \\
\hline 0 & $2.869,8 \mathrm{a}$ & $1.205,7$ & $72,1 \mathrm{a}$ \\
\hline 7 & $2.682,8 \mathrm{ab}$ & $1.018,7$ & $72,4 \mathrm{a}$ \\
\hline 14 & $1.743,3 \mathrm{~b}$ & 79,2 & $69,2 \mathrm{a}$ \\
\hline Testemunha sem controle & $1.664,1 \mathrm{~b}$ & - & $67,8 \mathrm{a}$ \\
\hline CV (\%) & 22,95 & 5,84 & 54 \\
\hline
\end{tabular}

DAS: dias após os primeiros sintomas; CV: coeficiente variável.

Médias seguidas de mesma letra não diferem entre si pelo teste Tukey a 5\% de probabilidade.

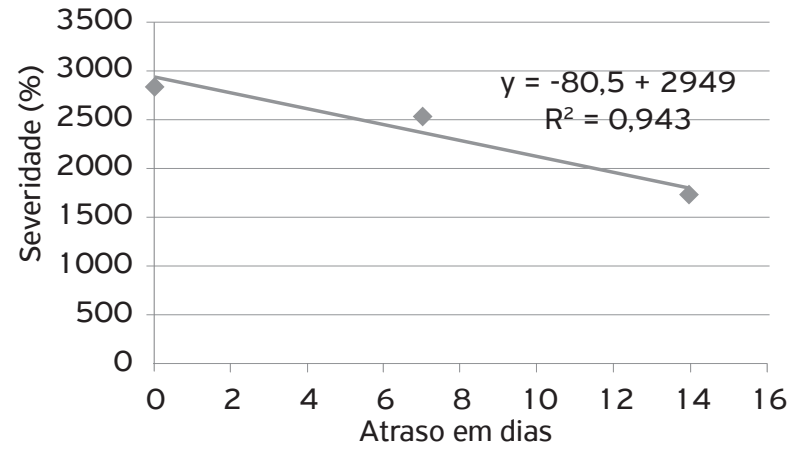

Figura 3. Regressão entre os índices de produtividade e o atraso em dias para a aplicação de fungicida para controle da ferrugem da folha do trigo.

da aplicação de fungicidas no momento correto em cultivares susceptíveis, ou seja, antes do início do desenvolvimento epidêmico da doença. Aplicaçóes tardias — sob maior pressão de inóculo - aumentam as chances do desenvolvimento futuro de resistência dos fungos aos fungicidas (Guini; Kimati, 2002).

A influência do atraso em relação ao momento inicial de aplicação foi estimada pela regressão entre a produtividade da cultura e o número de dias de atraso nas aplicaçôes (Fig. 3).

A estimativa demonstrou que os danos foram de $80,5 \mathrm{~kg} / \mathrm{ha}$ para cada dia de atraso no início das aplicaçôes de fungicida, número bastante superior aos encontrados por Cook et al. (1999) em trabalho sobre aplicaçôes sistemáticas de fungicidas na cultura do trigo nos Estados Unidos, os quais encontram níveis próximos a $27,2 \mathrm{~kg} / \mathrm{ha}$, ocasionados por diversas doenças concomitantemente, como septória, oídio, ferrugem da folha, etc.

No Brasil, informaçóes acerca de perdas provocadas por doenças do trigo são escassas. Porém, Picinini; Fernandes (1994; 1995) as relataram no Rio Grande do Sul (de até $44,23 \%$ ), ocasionadas por doenças fúngicas em geral, e até $80,00 \%$ pela ferrugem da folha no cultivar BR 34 . Deve-se lembrar que este tipo de informação, contido em tais trabalhos, é de caráter informativo, dando ao leitor uma ideia do dano que a doença pode gerar, pois a determinaçáo de tais níveis de perdas é dependente de diversos fatores: susceptibilidade do cultivar, virulência da raça fisiológica do patógeno, estádio da cultura em que a doença se inicia, taxa de progresso e formas de disseminação (Roelfs et al., 1992; Suba RaO et al., 1989), entre outros.

Todavia, tais resultados confirmam a importância do papel das doenças no sistema de produção do trigo como um todo quando analisamos a questão econômica. HirakURI (2011), em seu levantamento econômico da cultura do trigo para a regiáo de Londrina (PR) na agrícola de 2010, baseando-se no preço médio de $\mathrm{R} \$ 28$ a saca de $60 \mathrm{~kg}$ e em todos os custos do sistema produtivo envolvidos (insumos, serviços, administrativo e de oportunidade), considera que o ponto de equilíbrio da produção varia entre 2.850 e $2.890 \mathrm{~kg} / \mathrm{ha}$.

Assim, embora este levantamento não deixe claro o número de aplicaçôes de fungicida utilizado no cálculo, pode-se inferir que o tratamento referente à aplicaçáo nos primeiros sintomas (0 DAS) não apresentaria lucratividade alguma. Já o atraso nas aplicações em 14 dias representaria prejuízo de aproximadamente de R\$525,70 por hectare. Portanto, este dado denota claramente a importância do controle eficaz das doenças.

A lucratividade do sistema agrícola está apoiada em três pilares fundamentais: produtividade, preço de venda e custo de produção. A produtividade de uma cultura é dependente da interaçáo de inúmeros fatores, tais como disponibilidade de água e nutrientes no solo, condiçôes climáticas e ocorrência de pragas, plantas daninhas e doenças, etc. O preço de venda, por sua vez, varia de acordo com a da situação mercadológica mundial no momento da comercialização da safra agrícola. Já o custo de produção, condicionada à quantidade e ao preço dos insumos utilizados, pode ser amplamente alterado pelo agricultor, não resultando necessariamente em mudança nos níveis de produtividade. Neste contexto, estáo inseridos os sistemas de previsão de doenças que podem gerar informaçóes importantes para a tomada de decisão da aplicaçáo de fungicida pelo produtor rural, gerando reflexão de maneira substancial no custo de produção da cultura.

Por fim, os resultados deste trabalho demonstram que o atraso nas aplicaçóes de fungicida gera danos consideráveis, com perdas na ordem de $80,5 \mathrm{~kg} / \mathrm{ha}$ por dia de atraso na aplicação. 


\section{REFERÊNCIAS}

ARDUIM, G.S. Sensibilidade de raças de Puccinia triticina a fungicidas.2009. 91f. Tese (Doutorado em Fitopatologia). Universidade de Passo Fundo, Passo Fundo, 2009.

BOLLER, W.B.; FORCELINI, C.A.; HOFFMANN, L.L; CASA, R.T. Tecnologia de aplicação de fungicidas - parte II. Revisão anual de patologia de plantas, v.16, p.85-132, 2008.

BRUNETTA, D.; DOTTO, S.R.; FRANCO, F.A.; BASSOI, M.C. Cultivares de trigo do Paraná: rendimento, características agronômicas e qualidade industrial. Londrina: EMBRAPACNPSo, Circular Técnica, 18, 1997.

BUCK, J.W.; WISE, K.; DONG, W. Effect of postsymptom application of fungicides on urediniospore production by Puccinia triticina on wheat and $P$. hemerocallidis on daylily. The American Phytopathological Society, v.95, n.3, p.325-330, 2011.

CARDOSO, C.A.A. Desenvolvimento de um sistema de aviso para a brusone do trigo causada por Pyricularia grisea, 2006. 84f. Dissertação (Mestrado em Fitopatologia). Universidade de Passo Fundo, Passo Fundo, 2006.

COOK, R.J.; HIMS, M.J.; VAUGHANB, T.B. Effects of fungicide spray timing on winter wheat disease control. Plant Pathology, v.48, n.1, p.33-50, 1999.

DEBONA, D.; FAVERA, D.D.; CORTE, G.D.; DOMINGUES, L.S.; BALARDIN, R.S. Controle químico da ferrugem da folha em cultivares de trigo submetidas a diferentes níveis de adubação nitrogenada. Revista da FZVA, Uruguaiana, v. 16, n. 1, p.52-65, 2009.

DEL PONTE, E.M.; FERNANDES, J.M.C.; PIEROBOM, C.R.; BERGSTROM, G.C. Giberela do trigo - aspectos epidemiológicos e modelos de previsão. Fitopatologia Brasileira, Brasília, v.29, p.587-605, 2004.

EMBRAPA. Sistema brasileiro de classificação de solos. Brasília: Embrapa-CNPS, 1999. 412p.

GARDIANO, C.G.; BALAN, M.G.; FALKOSKI FILHO, J.; CAMARGO, L.C.M.; OLIVEIRA, G.M.; IGARASHI, W.T.; SUDO, L.T.; IGARASHI S.; ABI SAAB, O.J.G.; CANTERI, M.G. Manejo químico da ferrugem asiática da soja, baseado em diferentes métodos de monitoramento. Arquivos do Instituto Biológico, São Paulo, v.77, n.3, p.497-504, 2010.

GODOY, C.V.; OLIVEIRA, N.A.; PAIVA, S.B.; BASTOS, H.B. Eficiência do fungicida azoxistrobin no controle da ferrugem da folha e de manchas foliares do trigo. Summa Phytopathologica, v.26, n. 1, p.258, 2000.

GRASSO, V.; SIEROTZKI, H.; GARIBALDI A.; GISI, U. Characterization of the cytochrome $b$ gene fragment of Puccinia species responsible for the binding site of Qol fungicides. Pesticide Biochemistry and Physiology, v.84, n.2, p.72-82, 2006.
GUINI, R.; KIMATI, H. Resistência de fungos a fungicidas. Jaguariúna: Embrapa Meio Ambiente, 2002. 78p.

HIRAKURI, M.H. Avaliação econômica da produção de trigo no Estado do Paraná, para a safra 2011 . Londrina: Embrapa Soja, 2011.

IGARASHI, W.T.; CAMARGO, L.C.M.; IGARASHI, S.; GARDIANO, C.G., OLIVEIRA, G.M.; SAAB, O.J.G.A. Manejo químico da ferrugem asiática da soja, baseado em diferentes métodos de monitoramento. Fitopatologia Brasileira, v.34, p.98, 2008.

KUHNEM JUNIOR, P.R.; CASA, R.T; RIZZI, F.P.; MOREIRA, E.N.; BOGO, A. Desempenho de fungicidas no controle de doenças foliares em trigo. Revista de Ciências Agroveterinárias. Lages, v.8, n.1, p.35-42, 2009.

PICININI, E.C.; FERNANDES, J.M. Controle da ferrugem da folha e da mancha bronzeada da folha de trigo pelo uso de fungicidas em tratamento de sementes. Fitopatologia Brasileira, v.26, n.1, p. $100,2001$.

PICININI, E.C.; FERNANDES, J.M.C. Efeito da ferrugem da folha (Puccinia recondita f. sp. tritici) sobre o rendimento de grãos da cultivar de trigo BR 34 tratada com fungicidas. Fitopatologia Brasileira, v.19, p.286, 1994.

PICININI, E.C.; FERNANDES, J.M.C. Efeito de diferentes fungicidas sobre o rendimento de grãos, sobre o peso do hectolitro e sobre o controle da ferrugem da folha (Puccinia recondita f. sp. tritici), em trigo, cultivar BR 34. Fitopatologia Brasileira, v.20, p.319, 1995.

PIRES, P.C; FERNANDES, J.M.C; NICOLAU, M. Modelagem do progresso temporal e do padrão espacial de lesões de ferrugem da folha em trigo. Tropical Plant Pathology, v.34, n.2, p.97-107, 2009.

RAMOS, H.H.; PIO, L.C. Tecnologia de aplicação de produtos fitossanitários. In: Zambolim, L.; Conceição, M.Z.; Santiago, T. O que engenheiros agrônomos devem saber para orientar o uso de produtos fitossanitários. Viçosa: UFV, 2008. p.133-200.

ROELFS, A.P.; SINGH, R.P.; SAARI, E.E. Rust diseases of wheat: concepts and methods of disease management. Mexico: CIMMYT, 1992. 81p.

SHAH, D.A.; BERGOSTROM, G.C. A rainfall-based model for predicting the regional incidence of wheat seed infection by Stagonospora nodorum in New York. Phytopathology, v.92, n.5., p.511-518, 2002.

SUBBA RAO, K.V.; SNOW, J.P.; BERGGREN, G.T. Effect of growth stage and initial inoculum level on leaf rust development and yield loss caused by Puccinia recondita f. sp. tritici. Journal of Phytopathology, v.127, n.3, p.200-210, 1989.

YANG, X.B. Framework development in plant disease risk assessment and its application. European Journal of Plant Pathology, v.115, p.25-34, 2006. 